\title{
Success factors and challenges of an Information Communication Technology network in rural schools
}

Maryke A. Mihai

Department of Science, Mathematics and Technology Education University of Pretoria, South Africa

maryke.mihai@up.ac.za

\begin{abstract}
In April 2008, an interactive Information Communication Technology network was established in Mpumalanga, South Africa. The network involved the implementation of smart interactive whiteboards and collaboration between a leading school and several disadvantaged schools. The main purpose was to reach out to rural schools in the area in order to improve the teaching of Science and Mathematics for grade 12 learners. The purpose of our research was also to determine the success factors contributing to the survival of this project as well as the challenges that the interviewees had to face. The project studied is a model for other schools to emulate and is extremely successful in bridging the urban-rural divide.
\end{abstract}

Key words: challenges, disadvantaged schools, Information Communication Technology, interactive whiteboards, Science and Mathematics teaching, rural schools, success factors 


\section{Introduction}

In 2005, a school in Mpumalanga, South Africa, bought two interactive whiteboards (IWBs) and a technology teacher started experimenting with the use of one in his class. He could connect to his friend in England via the internet, and thought that, if this could be done, it should also be possible to link up with other schools in the region, but the rural and township schools did not have internet access. It was thought that if this could be provided, the knowledge and skills available in one school could be shared with other schools, thus benefiting the whole area. He shared his opinions and got his principal and a representative of the Mpumalanga Department of Education interested in his ideas. His school took a decision to develop an Information Communication Technology (ICT) learning environment that would link their own school with schools in disadvantaged areas. As a concept, it was unique to schools in South Africa. Realising the potential that such an initiative has, different sponsors came on board and provided funds. In April 2008, an interactive ICT network, implementing smart boards (interactive whiteboards or IWBs), was established, with the leading school and three previously disadvantaged schools as partners. The main purpose was to reach out to rural schools in the area in order to improve the teaching of Science and Mathematics for grade 12 learners. In 2013, the project expanded to transmit lessons to grade 11 learners as well.

In 2010, the project took a turn for the worse. The support from the Department of Education, that was vital to the success of the venture, dwindled and some of the sponsors withdrew their financial support as other priorities in the region superseded the importance of the project. The wireless network was also damaged by lightning and the leading school had to struggle to get a completely new system installed using sponsor money. Since 2011 , the system has 
been running without any major problems and two more schools have been added to the project.

Three of the schools are rural (within a $50 \mathrm{~km}$ radius), while two schools are in the town (within a $10 \mathrm{~km}$ radius). These five schools are connected to a central file server that is situated at the leading school. This file server contains all the Mathematics and Science resource materials such as lesson presentations, common tests and exams, recorded video lessons, as well as lesson notes for the remote teachers and students. The lesson notes are printed the day before the actual transmission and then handed out on the day of the lesson. During each session, the presenter records the lesson and it is saved on the file server for the purpose of revision or it can be downloaded on a memory stick for the students to take home.

\section{Purpose of the study}

The purpose of our research was to determine the success factors contributing to the survival of this project since 2008 , as well as the challenges that the interviewees had to face as a result of this initiative. We also concentrated on the management of the project, as it contributed to the sustainability of the project. We wanted to examine the relationships between the different role players and how they used their power to influence others and to contribute to the success or failure of the network.

\section{Using the interactive whiteboard in education and in this project}

Many educational institutions try to provide students with better learning opportunities by equipping schools with the latest technology. This encourages teachers to use assistive technologies such as computers and the internet and this process is called integration of ICTs. As part of the ICT integration process, the IWB has been invested in the most, especially by European countries (Turel \& Johnson, 2012). According to Kobus van Wyk, the programme 
director of the Khanya Education in Technology Project in the Western Cape, incorporating IWBs in a lesson has enhanced teaching and learning in ways we never imagined (News, 2011). This can also be seen in the Mpumalanga project.

Teachers remark upon the IWB's efficiency, flexibility and versatility, the opportunities to access countless multimedia sources and the ability to switch almost seamlessly between normal board work, video, other programmes and the internet using the pen, computer mouse and on-screen icons. In addition, they comment that they are able to manage the class more easily while using the IWB (Glover \& Miller, 2001). It has the potential to help learners to reason and think through scientific explanations alongside their teacher and fellow learners (Beauchamp \& Parkinson, 2005). The IWB gives learners the confidence to take part in lessons and they find it easier to express themselves using the whiteboard (Education \& Training, 2011). The uniqueness of IWB technology lies in the possibility for an intersection between technical and pedagogic activities, in the sense that it offers opportunities for making meaning through dialogic interaction with one another and physical interaction with the board (Smith, Higgins, Wall, \& Miller, 2005). Learners and teachers in this project emphasised that learners like to come to the front of the class to interact with the IWB.

Even though the advantages found in the literature seem to be numerous, there are certain drawbacks that one needs to take into account. Given the cost per IWB package, schools need to give serious consideration to the possible alternatives. Only if the IWBs are used to extend and transform learning can their cost be justified relative to cheaper solutions (Becta, 2004). In this project, the IWBs were mainly bought with sponsor money, as well as through budgeting by SGBs.

Teacher professional development is crucial. Teachers cannot be expected to experiment on their own after the initial hardware training. They need training in the most effective 
approaches in order to take full advantage of the technology (NCTE., 2008). This was also an aspect emphasised by the teachers in the project. Some of them thought that the initial training was adequate, but others felt that they needed more training. It is an area for which the leading school is chiefly responsible in terms of budget considerations.

Becta (2004) finds that the developing of multimedia teaching materials is a significant addition to workload in the early stages, and that the expectations that the whiteboard engenders in learners put pressure on teachers to constantly improve the presentation and content of lessons. This is also an aspect highlighted in the project. The expectations of the parents are much higher. Even in the most difficult teaching and learning environments, it is the teacher's willingness to change that "makes-or-breaks" an ICT deployment in schools (Slay, Sieborger, \& Hodgkinson-Williams, 2007).

Whereas the agenda in decision-making has previously tended to focus on the acquisition of ICT resources, there has been a shift towards how ICT should be used to support teaching and learning (Becta, 2007). The teachers in this project are definitely willing to take up the challenge of teaching and letting the learners learn in an IWB network. In the leading school, 'champions' introduced new approaches to teaching and learning and influenced their colleagues in their own and other schools by their example.

The London Challenge component of the Schools interactive Whiteboard Expansion project (SWE) substantially increased the number of IWBs in London secondary school core subjects like Mathematics and Science. It was found that IWB technology is used in most, if not all, lessons in these subjects and that the use of IWBs to visualise or dynamically represent abstract concepts in new ways has immediate relevance (Moss, Jewitt, Levačić, Armstrong, Cardini \& Castle, 2007). The literature suggests a continuum in which new technologies initially support, then extend and finally transform pedagogy as teachers gradually find out 
what the technology can do. There are three themes that dominate thinking about the role of IWBs in changing pedagogy, namely increased pace of delivery, increased use of multimodal resources and a more interactive style of whole class teaching. Both learners and teachers are very positive about the technology (Moss et al., 2007).

In a White Paper about interactive whiteboards and learning, research observations from the United States, United Kingdom and Australia are compared. It is indicated that the functionality of the IWB and its accompanying software allows for the development of classroom activities that are engaging for students, so they encourage greater focus, participation and interaction and improve student learning outcomes (SMARTTechnologies, 2006). IWBs appeal to both intrinsically and extrinsically motivated students. The requirements of visual, hearing-impaired and other special needs students can be addressed when lesson delivery and learning activities incorporate the use of an IWB. Educators are in agreement that IWBs improve a student's ability to retain and recall information presented in an IWB lesson activity. Once teachers have received training, ICT integration helps to streamline lesson preparation, increase teacher productivity and enhance student learning in the $21^{\text {st }}$ century classroom (SMARTTechnologies, 2006).

The European Social Fund funded IWBs for schools in the Czech Republic. Like other teachers, the Czech teachers realised that knowledge of the technical aspects alone is insufficient and that there is a need for new teaching and organisational methods to improve their overall competence (Martinkova, 2010). Enthusiasm and motivation on the students' part alone are not sufficient to improve their results unless the use of the IWB is paired with appropriate teaching techniques. Schools that used IWBs for more than two years showed advancements in the teachers' lecturing style, as well as overall progress in test results of all students that used IWBs (Martinkova, 2010). 


\section{Theoretical frameworks}

Basing its recommendations on data collected by the educational inspectorate, "Kennisnet ICT Op School" offers guidance to schools with respect to integrating ICT into their curriculum in a balanced and lasting way (Kennisnet, 2007). As a theoretical framework, it uses the "Four in Balance" Dutch model (see Figure 1), which reflects a scientifically researched vision for the implementation of ICT in schools. Key to this model is that, for pedagogical use of ICT to occur, there have to be certain structures in place.

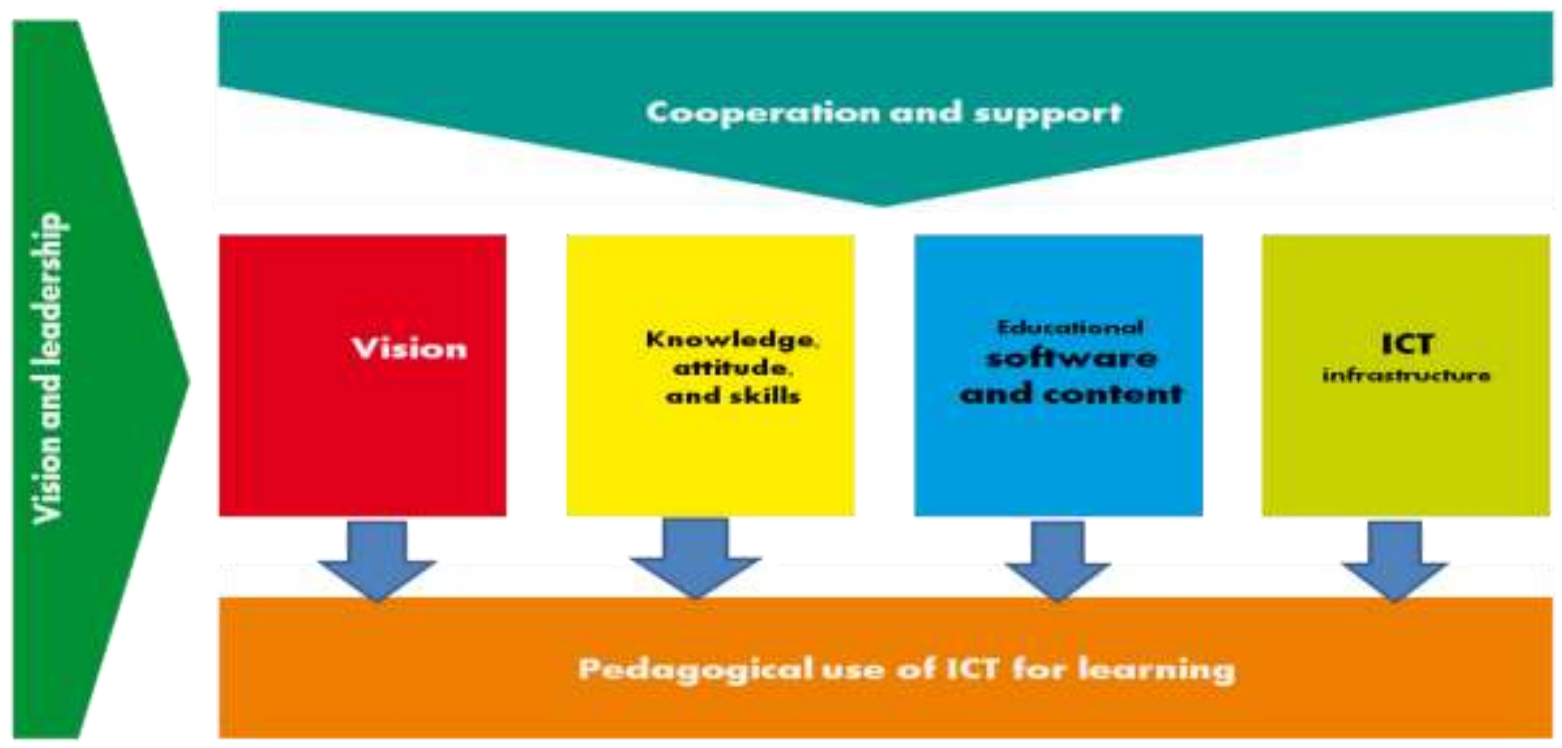

Figure 1: The Four in Balance Model

Source: Kennisnet (2007).

In the case of this project, cooperation and support are coming from the SGBs and the sponsors. The SGBs are very positive about the project, and agreed to allow it to be implemented in the schools. Some SGB members have also visited the schools to see how the project is developing. All the SGBs, together with the principals, are in control of the budgets. They are in charge of the security, insurance and buying of extra IWBs. Different sponsors are providing funds to sustain the project in participating schools. The project 
manager is primarily responsible for finding sponsors and the allocation of sponsorship money, which is the chief source of finance for the purchase and installation of new IWBs.

Vision and leadership mostly come from the principals. The principals need a strong vision for what the IWBs can bring to their school and play the leading role in the integration of the new technology in their schools and in the curriculum. A principal fulfils a visionary role when he or she understands how technology can be used in teaching and learning and establishes a context for technology in his/ her school (Brockmeier, Sermon, \& Hope, 2005). Their interventions have a considerable impact on the teachers' implementation of ICT (Schiller, 2011). The principal has to show a commitment to long term investment in technology and schools should have a learning and teaching team, co-ordinated by a member of the senior management team (SMT). The SMT needs to acknowledge the school development plan and be the bridge to classroom practice. The role of the SMT is to decide when and how the IWBs will be implemented into classrooms.

The project manager of the leading school supplies the vision for IWB integration in the different schools. He has a lot of power and, according to one of the principals, this project is his brain child. He is responsible for what, when and how things have to be accomplished, and is the overall manager, giving feedback only to his principal and SGB. He is responsible for having a clear project plan to reach performance targets, determining resource budgets, managing project risks, sustaining a focused and committed team, creating the team's operating practices, monitoring performance against plans, resolving interpersonal conflicts as well as project issues and problems, and controlling project changes (Portny, 2013).

The teachers transmit knowledge to the learners using the IWB as a media tool. Knowledge is based on the new CAPS syllabus for grades 11 and 12 in Mathematics, Mathematics Literacy and Science. The attitude of the teachers and learners regarding the new technology is highly 
significant. The attitude of the learners changed towards traditionally "difficult" subjects and they now regard them as not only doable, but also as subjects wherein they can achieve and receive bursaries for further study. Experiments in Science have become more accessible. The teachers and learners are motivated to use the IWB in class. Learners enjoy coming to the whiteboard and they are not shy to write on it in front of the class. They are interacting with the whiteboard and it offers increased opportunities to collaborate with others. Teachers and learners are acquiring the necessary skills to use the whiteboard. Teachers are receiving training in the use of the software and hardware. Training enables teachers to embrace the powerful possibilities of the new technology (Betcher \& Lee, 2009).

The IWBs come with their own educational software, included in the price of the boards, and upgrades are free. It is possible to use this software together with the South African CAPS content. The teachers have the choice to develop their own original content or to utilise precreated lessons in the software.

The ICT infrastructure refers to the computer hardware, in this case the interactive whiteboards themselves, as well as the computers and projectors. It also incorporates the software needed to manage the administrative and management tasks in the network, what kind of network is used, computer security and the maintenance in the network.

All these components work together to establish pedagogical use of ICTs. The IWBs are used in fully interactive ways that are able to bring together digital resources like text, images, audio, video, and an infinite collection of resources from the web (Betcher \& Lee, 2009). The IWBs have become as much a part of the classroom as the blackboards were, supplementing and enhancing good quality teaching. The technology is used to create better learning experiences for the learners. 
The SAMR model is designed to help educators infuse technology into teaching and learning (Schrock, 2013). In the IWB project in Mpumalanga, the IWBs given to the schools allowed for significant task redesign from the outset, as teachers were trained in the use of the new technology, and it brought transformation to their classes, especially in Science, where experiments became accessible to learners who previously had to learn from old magazines. The teachers also moved to redefinition of tasks, where the technology is used to add value to the learning process. The teachers of the leading school are creating new lessons to transmit, using a range of resources to enhance the learning process. Learners are centrally involved in the use of the technology and their interest is captured through providing information in a range of different formats. The IWBs enable a smoother presentation of curriculum content than ever seemed possible. Their flexibility allow teachers to respond spontaneously to what happens as a lesson proceeds.

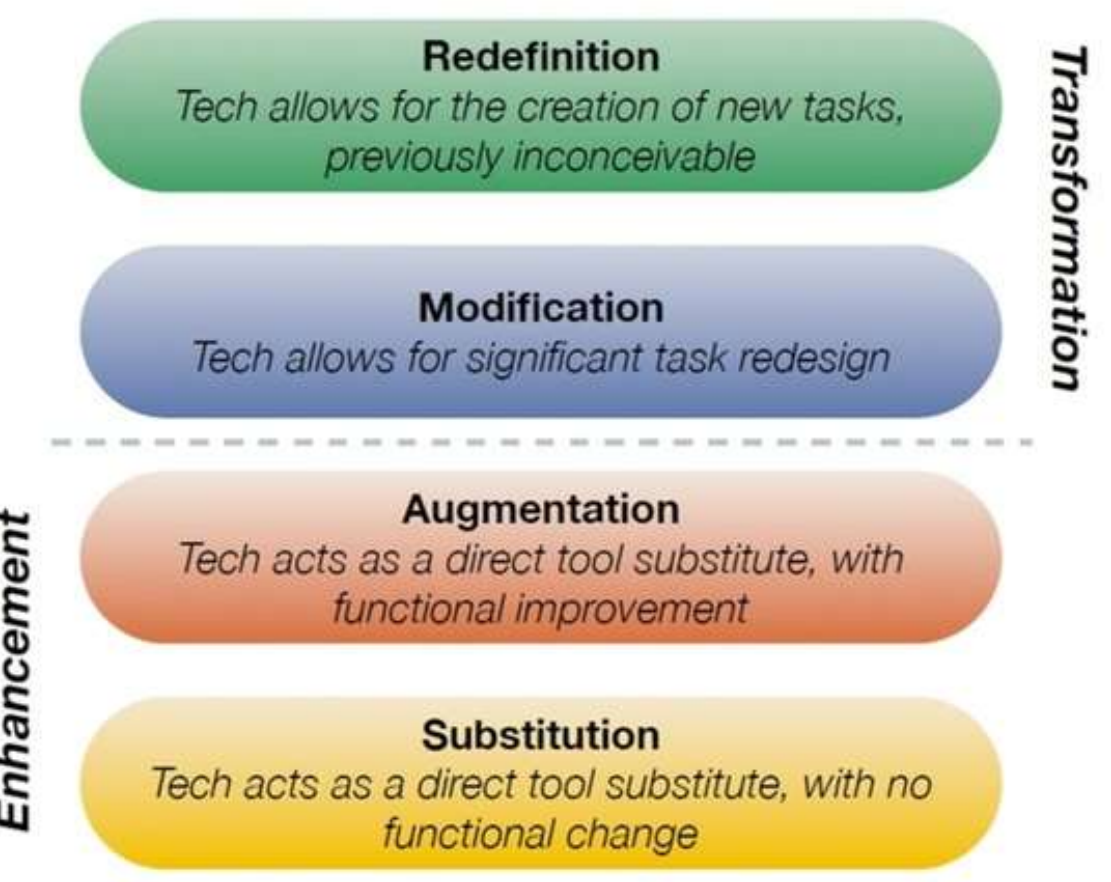

Figure 2: The SAMR model

Developed by Dr. Ruben Puentedura. Source: Schrock (2013). 


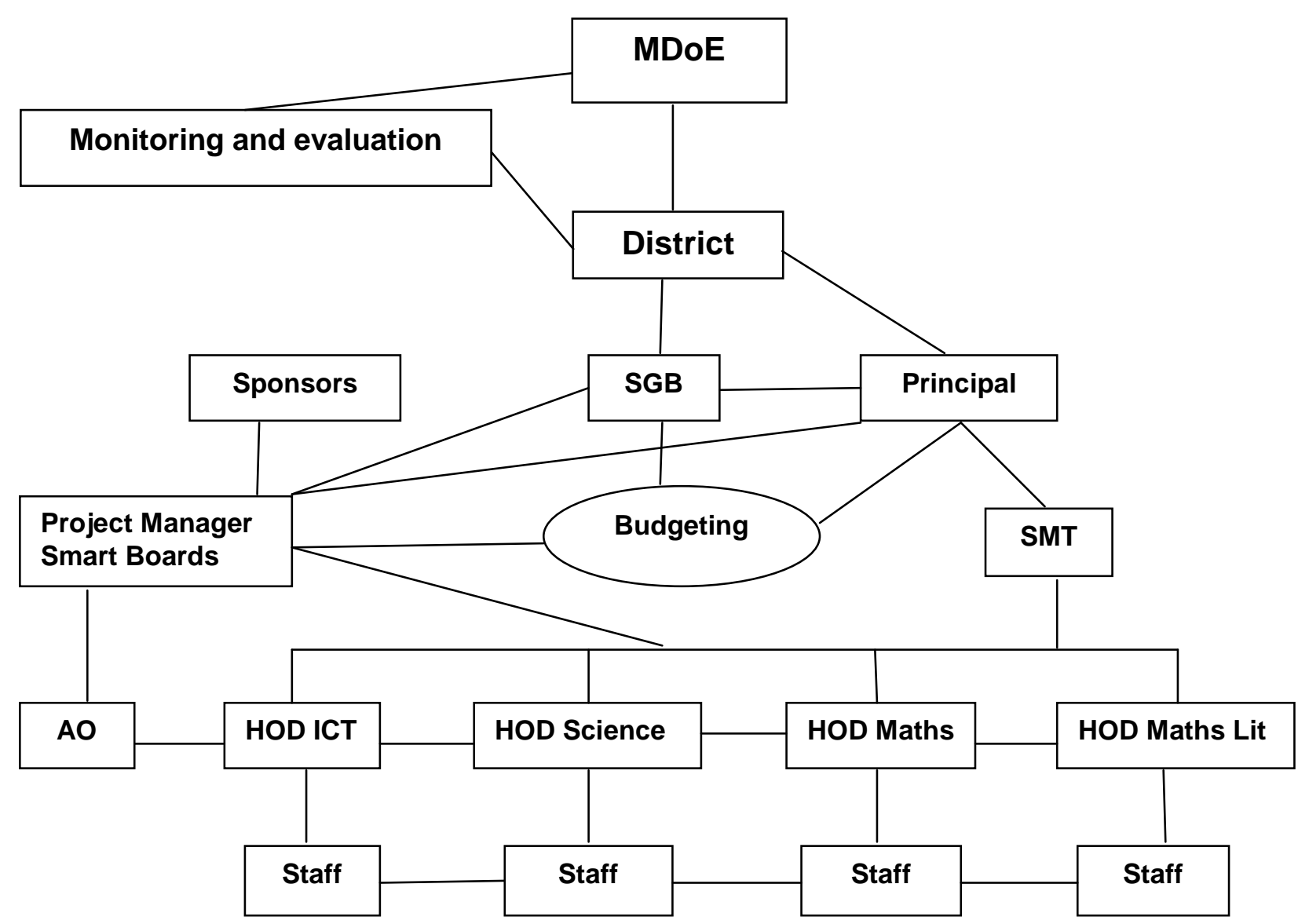

Figure 3: A balanced matrix management project

Adapted from: Akrani, Katyani \& Patil (2010) and Edgeli (2007).

Figure 3 illustrates the complexity of the matrix management structure of an ICT project. The MDoE is outside the matrix and responsible for the monitoring and evaluation of the project. Each school has its own internal management structure, with its own SGB and principal, who need to take decisions pertaining to the vision and financial implications of the project. The SMTs are in charge of the other management functions. Cutting across this, is the ICT project that involves a number of schools, with the project manager responsible for the overall management of the project. This structure is typical of a balanced matrix structure, where all 
the teachers report to at least two managers - the functional (HODs, vertical flow) and the project manager and administrative officer (AO) (horizontal flow). The sponsor money is mostly used for new smart boards and maintenance. It also provides paper, although never enough. In the rural schools, the school fees are very low, and school budgets, controlled by the principal and SGB, are used for buying more IWBs, security, insurance, upgrades and paper.

All the administrative reports in the project, as well as most of the reports of the teachers and HODs, go to the administrative officer. All the results from common tests are sent to her before the meetings, so that she can analyse them and determine whether there has been an improvement or not, a mechanism that effectively also monitors the teachers' progress. She ensures that everybody knows the schedules and gets their calendars, and she handles any administrative complaints. According to the project manager, she plays a key role, and his words are echoed by all the teachers

The HODs of the leading school, one of the teachers at the leading school, and one rural teacher (for Mathematics Literacy) handle the transmissions of the lessons. They formed subject groups for their subjects, and the teachers and HODs of the rural schools report to them in their subject groups. The teachers of the rural schools also report to their respective HODs, who in turn report to their principals. According to the representative of the MDoE, this cannot be done by outsiders, since the rural schools have their own school management system. The principals tell their staff how to manage their classes and the project is just there as extra help for them.

\section{Research design}

This was a qualitative descriptive case study. The research design was based on the researcher's assumptions, research skills and practices (Nieuwenhuis, 2007). Qualitative 
research looks at cultural and social experiences, relationships between occurrences and the significance of events as they affect specific human endeavours (Kincheloe, 2012). One of the goals of a qualitative study is description. The primary aim of our research was to provide an in-depth description of the management changes and challenges in the project. The six schools in Mpumalanga formed the case. This is a single case study design, an example of school innovations in which an individual school adopted an innovation, in this case the IWB network. This is an intrinsic case study and the particular case became interesting as a result of its uniqueness (Berg, 2001). We interviewed thirty interviewees, including School Government Body members (SGBs), principals, the project manager in the leading school and project coordinators in the rural schools, the administrative officer in the leading school, Heads of Departments (HODs) and teachers teaching Mathematics, Science and Mathematics Literature. We did not interview any learners, but the teachers commented on how the learners experience the network. The interview guide was prepared to ensure that basically the same information was obtained from each person, but we also used probes within these predetermined areas (Hoepft, 1997). The content of documents was explored systematically to look at themes related to the research questions.

\section{Findings}

The two main aspects arising from the interviews were positive changes as a result of the new network operating in the schools and the challenges associated with it. We quantified the number of responses, because they were an indication of the relative importance of the different aspects coming out of the interviews. We used the process called enumeration (to produce a counted list) to get to the data in the following two figures. In figure 4, the positive changes are shown. The amount of responses by interviewees is indicated on the bars of the graph. 


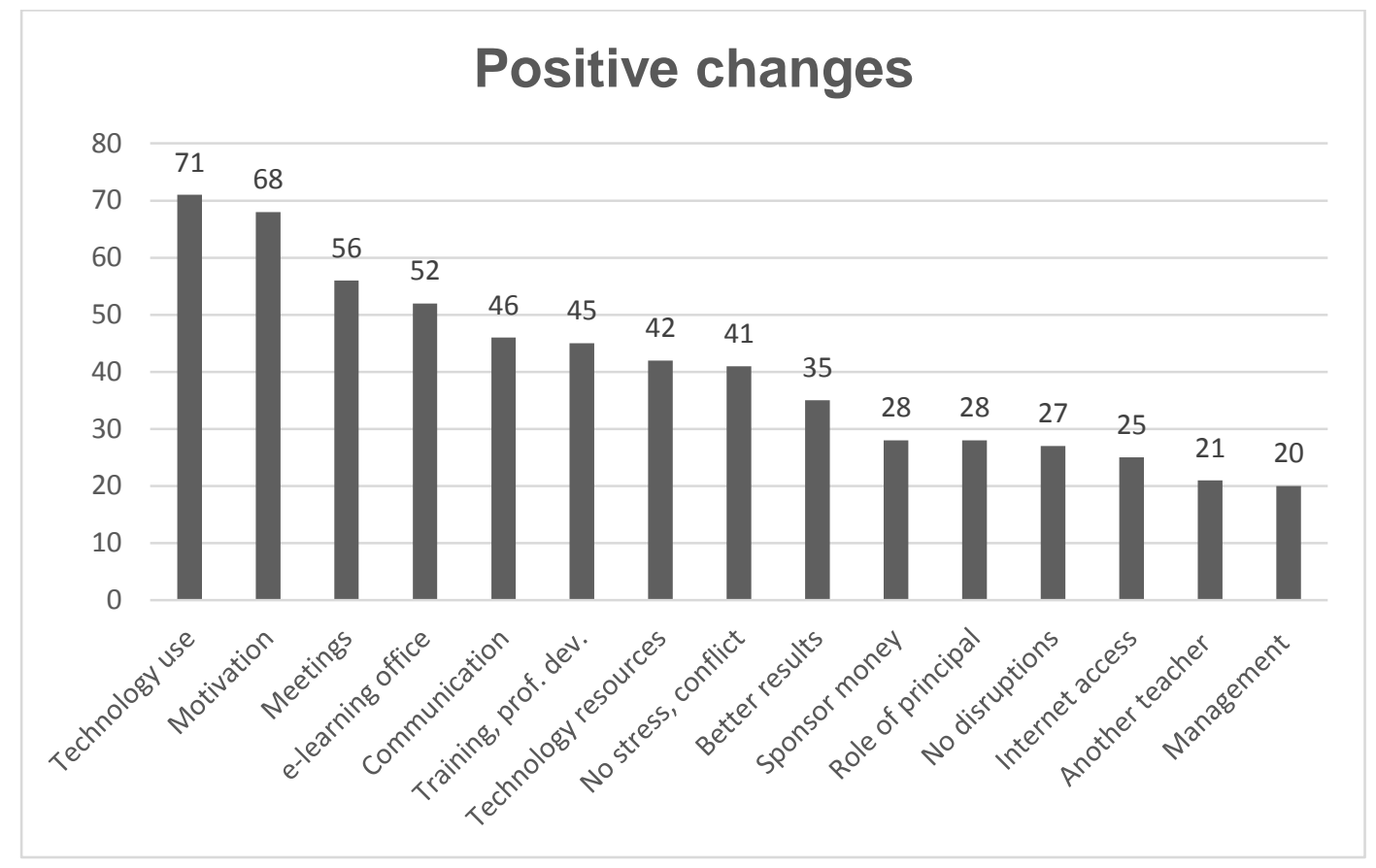

Figure 4: Positive changes as a result of the network

The technology use by teachers (forty six responses) and learners (twenty three responses) of computers and the IWBs peaked. The teachers and learners became more computer literate. As a result of the technology resources and the influence of the project on schools, teachers and learners are more motivated. Teacher motivation were mentioned in thirty six quotes, and learner motivation in thirty two. The network is operating very well as a result of quarterly meetings being held by all schools, at various venues. In the first meeting of the year, the yearly plan is set up. The leading school has an e-learning office to manage all the challenges and the programme. At the helm of this office is the project manager of the leading school, who is the most important manager, responsible for securing sponsor money for the project. There is also an administrative officer, to whom all the reports of the marks go, an IT administrator, who must oversee the working of the computers and the network, and the technicians, who do the physical work, putting the computers and upgrades in place. 
According to forty six responses, the communication between teachers improved as a result of collaboration in subject groups. Due to topic discussions with teachers, the teacher training programme also became more effective. Everyone sees training as very important, and most teachers considered the training provided by the leading school as adequate. The teachers mentioned the importance of professional development. They also sit in on the transmissions and learn new methods of presenting the work. Some of the teachers in the rural schools are not qualified to teach Mathematics or Science for grade 12 learners and they are also getting trained during the transmissions.

The fact that the schools receive resources like IWBs and computers were mentioned favourably by forty two quotes. Internet access is seen as a positive addition to the class situation, contributing to the teacher and learner motivation. The teachers, HODs and principals reported overwhelmingly that there were no disruptions as a result of the project. Going hand in hand with this, most reported no stress, conflict or confusion, mainly thanks to the meetings and yearly plan that everyone follows.

One of the most positive results of the project is the fact that learners obtain better results in Science, Mathematics and Maths Literacy, and that they receive bursaries for further study. The most important goal of the project is to obtain a $100 \%$ pass rate. Amongst the documents obtained, I received the results of schools, some from 2008 and others from 2010. In 2013, one of the rural schools obtained a $100 \%$ grade 12 pass rate, another $90 \%$ and another $85.7 \%$. One of the schools, in 2008, had 4 learners passing with admission to a Bachelor's degree, but in 2013, this number had increased to 28. Another school had 10 in 2008, 22 in 2013. One school had a grade 12 Science pass rate of $24 \%$ in 2010 and $95 \%$ in 2013; one had a Mathematics pass rate of $19 \%$ in 2010 and $100 \%$ in 2013. Although every year is different, it is clear that this project is already showing signs of bridging the urban-rural digital divide. 
This network relies mainly on sponsor money. Sponsors are investing in human capital and all the schools are benefitting and reporting a very close relationship with the sponsors. There were twenty eight highly favourable responses from the interviewees regarding the sponsors, who are seen as playing the most important part in the success of the project.

The principal is the person playing the most important role in the schools. Most teachers report that learners like to hear transmissions by other teachers than their own, since another way of doing things helps them to understand better. Twenty references to positive management processes were made.

It is seen as a great advantage that lessons can now be saved and replayed if learners were absent. Positive comments were made about the subjects involved, which are traditionally seen as very difficult, but learners are able to master them as a result of the network. Maintenance done by the leading school is seen as positive - the rural schools can trust the technical support from the leading school.

In figure 5, the challenges mentioned by interviewees are shown. The number of references to challenges is much less than those to positive incidents. The lack of money is seen as the biggest challenge. The Mpumalanga Department of Education (MDoE) only pays teachers' salaries and has a paper budget. Most of the money comes from sponsors, primarily obtained through presentations from the project manager of the leading school. Money for security and insurance need to come from a very limited school budget. 


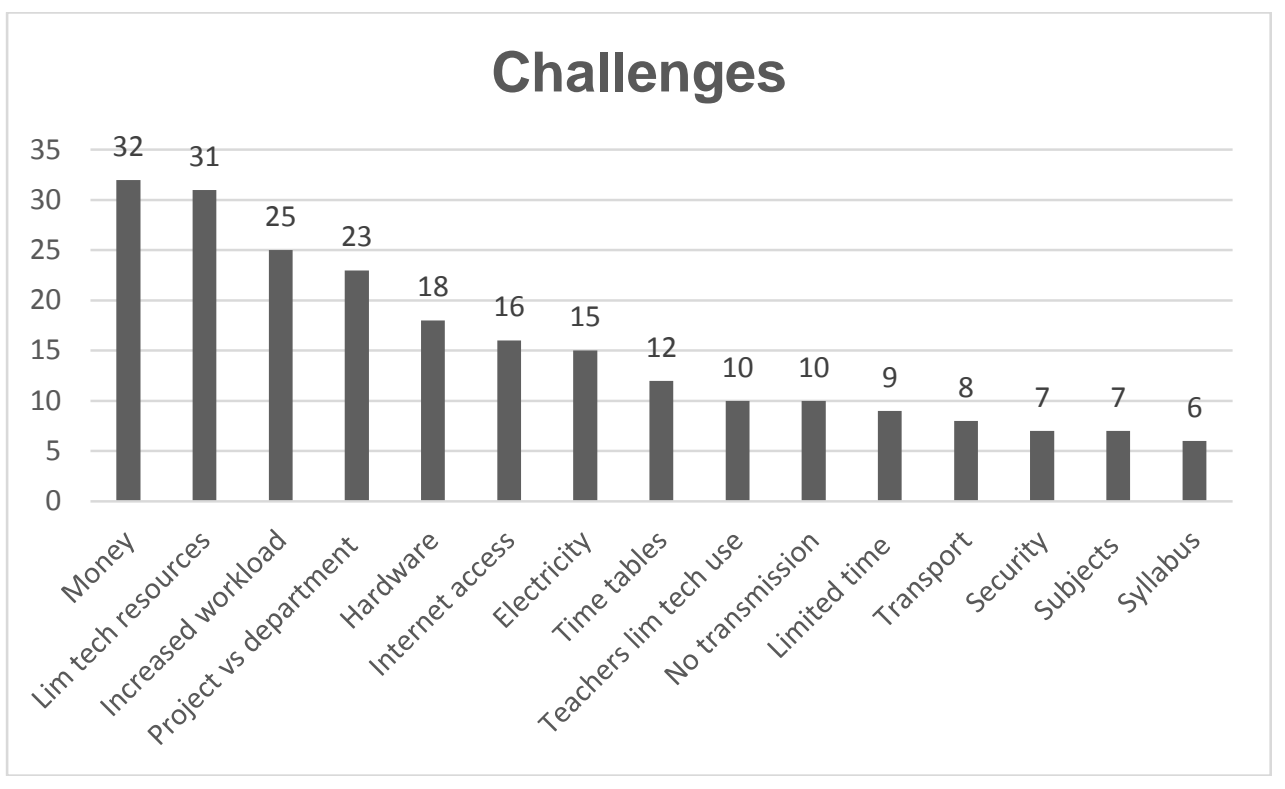

Figure 5: Most important challenges in the network

Limited technology use and resources, including insufficient computers, IWBs, scanners, photocopy machines, printers and data projectors, were mentioned as big challenges, in addition to hardware that is broken, stolen, or requiring an upgrade. All the interviewees at the leading school and some at the rural schools mentioned an increased workload. The increased workload is due to more assessments, as a result of common assessments written by all schools, therefore everybody has more marking. The teachers in the leading school draw up the common assessments and must also prepare for the transmissions, which takes about six hours for each one hour lesson to be transmitted. The difference between the programmes of the project and the Department was mentioned as a challenge by many teachers, although the pace and curriculum order dictated by the Department should be followed. Some also mentioned stress as a result of the difference.

The fact that internet access now exists in all the schools is an advantage, but the internet is often down as a result of electricity interruptions at the rural schools, also leading to no transmissions. Internet access is a problem in schools with too few computers available for 
learners; one school has only two computers, another four to share between 1200 learners. Limited time for doing transmissions, and extra time spent to reteach lessons if learners did not understand, are also problematic. Transport is also a problem - one of the schools has learners transported by busses coming from six different directions, and busses are often late for the transmissions taking place between 8:00 and 9:00, but the lessons are saved on the network so that the rural schools can go back to them later. Security is a challenge, mostly for the rural schools.

Some teachers see the subjects involved as a limitation, and are of the opinion that the project should involve more subjects, like Life Sciences, Accounting or Business Economics, because the learners in these subjects feel belittled because they cannot attend the programme. The new CAPS syllabus and the time involved to get through the grade 12 syllabus are mentioned as challenges in the project.

According to the representative of the MDoE, the project has reached capacity. They cannot add more schools because funding is getting scarce. In addition, time is a problem and schedules in rural schools have become tight. The project can however expand with respect to content and subjects taught.

Schools are likely to be much more effective if they are well managed. Successful ICT projects are the exception rather than the rule, and the fact that this one continues to expand, can mainly be attributed to good management. Each school retained its own management structure, but had to create the possibility of managing the ICT network across traditional boundaries. The management of this project is not confined to the principal. The principals and SGBs and the project manager of the leading school are the senior managers, and HODs are subject group leaders and functional managers. 
My first assumption was that, in this case, the cluster of schools would set up a matrix management structure with a project manager in each school to take care of the ICT smart board community network, and that specialist teachers in Mathematics and Science would be dedicated exclusively to this project. A matrix system evolved in the leading school, with dual reporting lines - vertically to the principal, and horizontally to the project manager and administrative officer. In the other schools, reporting takes place to the project team of the leading school across school boundaries, but within their own schools, the reporting stayed mostly the same as before, namely linear reporting from teachers to HODs to principals.

\section{Limitations}

This study was a single case study consisting of six high schools in Mpumalanga, South Africa, bound together into a cluster formed by their involvement in the same ICT network. Experiences within the cluster studied brought to the fore particular successes and challenges and exemplars of how these challenges were managed. The findings and solutions found in this case study are particular to the specific case, but may provide information to people involved in similar ventures.

\section{Recommendations}

In South Africa, we need more research into ICT integration in education and in the curriculum specifically, as well as the disparities between developed and developing countries and the bridging of the urban-rural divide. In this study, we concentrated on the use of the IWB, but research on the use of mobile technology like IPads and response systems used by learners to indicate their level of understanding, is also needed. The redress of education in rural areas requires integrated planning and implementation with the 
participation of local government and communities. The role of all stakeholders needs to be researched.

We need more research about the principal's role in implementing ICTs in the classroom. It is not enough to just allow technology in schools. Principals need to play an effective role in the management of the technology, ensuring that training takes place, going for training themselves, and ensuring that the technology is utilised by the teachers. Without a thorough understanding of computer technology's capabilities, principals will not be ready to provide the leadership in technology necessary for the restructuring of schools. Research on how the vision and mission of schools relates to principals, SGBs and ICT is also needed. Principals need to work with SGBs to explore the vision and mission of the school and how it relates to ICT. Managers decide how to use the organisation's resources and their decisions directly impact on the socio-economic situation of a society. Principals need to adjudicate between competing priorities and determine how to resource new initiatives.

In this project, traditional and matrix organisational reporting lines exist next to each other. Differences and similarities between bureaucratic and organic organisations should be investigated further, and how to bring about a shift in thinking, where concepts like control, order, power and hierarchy must be replaced by trust, mutual respect, and acceptance of the on-going process of organisational educational change.

Solutions can be investigated for the challenges noted, like financing, increased workload due to more assessments, the organisational challenges of the project versus the Department, lack of technology resources like insufficient computers, external challenges like transport, resources challenges like upgrades or not enough classrooms, subject restrictions which exclude subjects other than Maths and Science, time challenges like re-teaching learners, time table challenges to fit the project into all the schools' timetables. 
Learners and teachers can be observed while they are using the IWB network, for example, in the October holiday school, and then interviewed. Different learning styles can be identified and the influence of the use of the technology on learners with different learning styles investigated. The participation of different schools can be compared.

A historical study can be done and the changes from 2008 until present can be investigated. Lessons learnt in this project can also be applied to the new networks started in Mpumalanga.

In our study, we only used description as a tool. Explaining can be done of findings or why such a model developed, why the influence of SGBs is very limited or why the realities of the respective role players present themselves in a particular way.

\section{Conclusion}

Technology integration in this project was not only about technology, but about focusing on a change in pedagogy and increased learner achievement. IWBs in schools helped to change teacher pedagogies and provide students with better learning opportunities. IWBs have a lot of benefits, but certain disadvantages were also discussed. The Four in Balance and SAMR models as well as matrix management were adapted as theoretical frameworks for this study. The purpose of the research was to determine the success factors contributing to the survival of this project, as well as the challenges that the interviewees had to face as a result of this initiative. In the findings section, these positive changes and challenges were discussed. Recommendations for further research were also suggested. This Mpumalanga project is worthy of more research endeavours, and novel research possibilities exist in the expansion of the project to other regions. 


\section{References}

Akrani, G., Katyani, M., \& Patil, M. (2010). Elements of Management Process. Retrieved from http:kalyancity.blogspotcom/2010/06/management-functions-process-management.html

Beauchamp, G., \& Parkinson, J. (2005). Beyond the 'wow' factor: developing interactivity with the interactive whiteboard. School Science Review, 86(316), 97-104.

Becta. (2004). Getting the most from your interactive whiteboard: A guide for primary schools. Coventry, UK.

Becta. (2007). The impact of ICT in schools- a landscape review. Glasgow, UK: University of Strathclyde.

Berg, B. L. (2001). Qualitative research methods for the social sciences (4th ed.). USA: Allyn and Bacon.

Betcher, C., \& Lee, M. (2009). The Interactive Whiteboard Revolution: Teaching with IWBs. Australia: ACER Press.

Brockmeier, L. L., Sermon, J. M., \& Hope, W. C. (2005). Principal's Relationship with Computer Technology. NASSP Bulletin, 89(643), 45-63.

Edgeli, R. (2007). Managers-Net. Retrieved 4 April, 2013, from http://www.managersnet.com/matrixman.html

Education, \& Training. (2011). South African students engage in learning with SMART Board interactive whiteboards.

http://www.commonwealthministers.com/special reports/south african students engage in learn ing with smartboard interactive whiteboard

Glover, D., \& Miller, D. (2001). Running with Technology: the pedagogic impact of the large-scale introduction of interactive whiteboards in one secondary school. Journal of Information Technology for Teacher Education, 10(3), 257-276.

Hoepft, M. C. (1997). Choosing Qualitative Research: A Primer for Teaching Education Researchers. Journal of Technology Education, 9(1).

Kennisnet. (2007). Four in Balance Monitor 2007: ICT in Education in the Netherlands. Zoetemeer.

Kincheloe, J. L. (2012). Teachers as Researchers: Qualitative inquiry as a path to empowerment (Classic ed.). USA and Canada: Routledge.

Martinkova, A. (2010). Interactive White Boards: Cooperation between Universities and Primary and Secondary Schools. Paper presented at the ERIE.

Moss, G., Jewitt, C., Levacic, R., Armstrong, V., Cardini, A., \& Castle, F. (2007). The Interactive Whiteboards, Pedagogy and Pupil Performance Evaluation: An Evaluation of the Schools Whiteboard Expansion (SWE) Project: London Challenge. University of London: School of Educational Foundations and Policy Studies, Institute of Education.

NCTE. (2008). NCTE Advice Sheet- Interactive White Boards. Retrieved 10 September, 2012, from www.ncte.ie/ICTAdvice

News, S. A. (2011). Interactive whiteboards foster digital inclusion. http://www.sagoodnews.co.za/indez2.php/option=com content\&task=view4311

Nieuwenhuis, F. J. (2007). Introducing qualttative research. In K. Maree (Ed.), First steps in research. Pretoria: Van Schaik Publishers.

Portny, S. E. (2013). Project Management: Key Players in a Matrix Environment. Retrieved 4 April, 2013 , from http://www.dummies.com/how-to/content/project-management-key-players-in-a-matrixenvironment

Schiller, J. (2011). Interventions by school leaders in effective implementation of information and communications technology: perceptions of Australian principals. Journal of Information Technology for Teacher Education, 11(3), 289-301.

Schrock, K. (2013). Kathy Schrock's Guide to Everything. Retrieved 22 April 2015, from http://www.schrockguide.net/samr.html

Slay, H., Sieborger, I., \& Hodgkinson-Williams, C. (2007). An investigation into the use of Interactive Whiteboards in South African schools. IADS: International Journal on Computer Science and Information Systems, 3(2), 78-94.

SMARTTechnologies. (2006). Interactive Whiteboards and Learning: Improving student learning outcomes and streamlining lesson planning.

Smith, H. J., Higgins, S., Wall, K., \& Miller, J. (2005). Interactive whiteboards: boon or bandwagon? A critical review of the literature. Journal of Computer Assisted Learning, 21, 91-101.

Turel, Y. K., \& Johnson, T. E. (2012). Teachers' Belief and Use of Interactive Whiteboards for Teaching and Learning. Educational Technology and Society, 15(1), 381-394. 